\title{
EFICIÊNCIA DE UM HIDROCICLONE DE GEOMETRIA "RIETEMA" PARA PRÉ- -FILTRAGEM DE ÁGUA PARA IRRIGAÇÃO
}

\author{
OTHON C. DA CRUZ ${ }^{1}$, JOSÉ R. ZANINI ${ }^{2}$
}

\begin{abstract}
RESUMO: O hidrociclone é um equipamento amplamente utilizado pela indústria em processos envolvendo separação sólido-líquido, porém ainda pouco utilizado na agricultura irrigada no Brasil. Neste trabalho, avaliou-se o desempenho deste equipamento como pré-filtrante de partículas sólidas, oriundas dos processos erosivos e do assoreamento dos recursos hídricos. Os testes foram realizados com um hidrociclone de geometria "Rietema", possuindo diâmetro de 19,2 cm na parte cilíndrica, operando com vazões variando entre $10 \mathrm{~m}^{3} \mathrm{~h}^{-1}$ e $27 \mathrm{~m}^{3} \mathrm{~h}^{-1}$. Os materiais particulados usados em suspensão foram: solo franco-argiloso e areia de rio. Os resultados mostraram que a perda de carga máxima média foi de $52 \mathrm{kPa}$ e $47 \mathrm{kPa}$ para as suspensões aquosas de areia e solo, respectivamente. Seu melhor desempenho ocorreu operando com suspensão aquosa de areia, apresentando eficiência total de $92,3 \%$ para a vazão de $26,9 \mathrm{~m}^{3} \mathrm{~h}^{-1}$. Concluiu-se que o equipamento avaliado é mais eficiente para remoção de partículas de areia, podendo ser utilizado como pré-filtro em sistemas de irrigação.
\end{abstract}

PALAVRAS-CHAVE: separação sólido-líquido, pré-filtro, irrigação localizada.

\section{EFFICIENCY OF A HYDROCYCLONE OF "RIETEMA"GEOMETRY FOR PRE- FILTERING OF WATER FOR IRRIGATION}

\begin{abstract}
The hydrocyclone is an equipment widely used by industry in cases involving solidliquid separation, but still little used in irrigated agriculture in Brazil. This study evaluated the performance of this equipment as a pre-filter of solid particles, from erosive processes and the silting of water resources. The tests were performed with a hydrocyclone of "Rietema" geometry, with a diameter of $19.2 \mathrm{~cm}$ at the cylindrical part operating with outflows ranging between $10 \mathrm{~m}^{3} \mathrm{~h}^{-1}$ and $27 \mathrm{~m}^{3} \mathrm{~h}^{-1}$. The materials used in particulate suspension were clay loam soil and sand from river. The results showed that the average maximum head loss was $52 \mathrm{kPa}$ and $47 \mathrm{kPa}$ for aqueous suspensions of sand and soil, respectively. Its best performance occurred operating with slurry of sand, presenting total efficiency of $92.3 \%$ for $26.9 \mathrm{~m}^{3} \mathrm{~h}^{-1}$ of flow rate. It was concluded that such equipment is most effective to remove particles of sand, thus it can be used as a pre-filter in irrigation systems.
\end{abstract}

KEYWORDS: solid-liquid separation, pre-filter, localized irrigation.

\section{INTRODUÇÃO}

O uso intensivo do solo para atividades agrícolas sem o devido cuidado com a conservação ambiental culmina com a degradação das microbacias. Esses impactos são caracterizados principalmente pelo efeito erosivo do solo, resultando no assoreamento e na deterioração da qualidade da água dos mananciais, reduzindo os potenciais quantitativo e qualitativo de uso para a irrigação. Atualmente, como as águas superficiais não oferecem volumes e qualidade satisfatória devido ao uso máximo, opta-se pela perfuração de poços e muitas vezes o bombeamento é tão intenso que as águas dos aquíferos vão esvaindo-se, a ponto de provocar afundamentos do solo em algumas regiões (THAME, 2000). Em determinados casos, tem-se verificado grande concentração de sólidos grosseiros (areia) nas águas utilizadas para fins de irrigação, o que tem comprometido a eficiência dos sistemas, principalmente no que se refere à obstrução dos emissores.

\footnotetext{
${ }^{1}$ Prof. Dr. Efetivo, IF Triângulo Mineiro, Câmpus Uberaba, Fone: (0XX34) 3319.6051, othon@ifrtiangulo.edu.br.

${ }^{2}$ Eng ${ }^{\circ}$ Agrônomo, Prof. Dr., Departamento de Engenharia Rural, FCAV/UNESP - Jaboticabal - SP, jrzanini@ @cav.unesp.br. 
Segundo AYERS \& WESTCOT (1991), a quantidade e a qualidade são parâmetros importantes a serem considerados na irrigação, uma vez que, dependendo das características físicas, químicas e biológicas da água, o seu uso pode tornar-se limitado ou até inviabilizado. Os constituintes da água, sejam de origem natural ou antropogênica, conferem características qualitativas que podem influenciar no dimensionamento e na escolha do sistema de irrigação, bem como de filtragem (THOMPSON et al., 1983). Um dos principais problemas de qualidade da água para a irrigação e que está relacionado com a operação dos equipamentos é a obstrução física de tubulações e emissores, sobretudo em sistemas de irrigação localizada, em que os orifícios de passagem são de pequenos diâmetros (NAKAYAMA \& BUCKS, 1991). Contudo, diferentes tipos de filtros podem ser utilizados para minimizar o problema decorrente da presença de sólidos em suspensão na água de irrigação, sendo que os sistemas de filtragem podem ser constituídos por filtros de areia, de tela ou de discos (BERNARDO et al., 2005). Nas situações em que a água apresenta alta quantidade de sólidos, pode ser necessária a instalação de estruturas e/ou equipamentos como bacias de sedimentação ou pré-filtros instalados na tomada de água, antes do sistema de filtragem. Dentre esses, são citados os hidrociclones, que podem desempenhar esse papel, e que são instalados no cabeçal de controle.

O hidrociclone consiste em uma parte cônica, ligada a uma parte cilíndrica, na qual existe uma entrada tangencial para a suspensão de alimentação. A parte superior do hidrociclone apresenta um tubo para saída da suspensão diluída (overflow) e, na parte inferior, há um orifício de saída da suspensão concentrada (underflow), conforme esquema da Figura 1 (SOUZA et al., 2000).
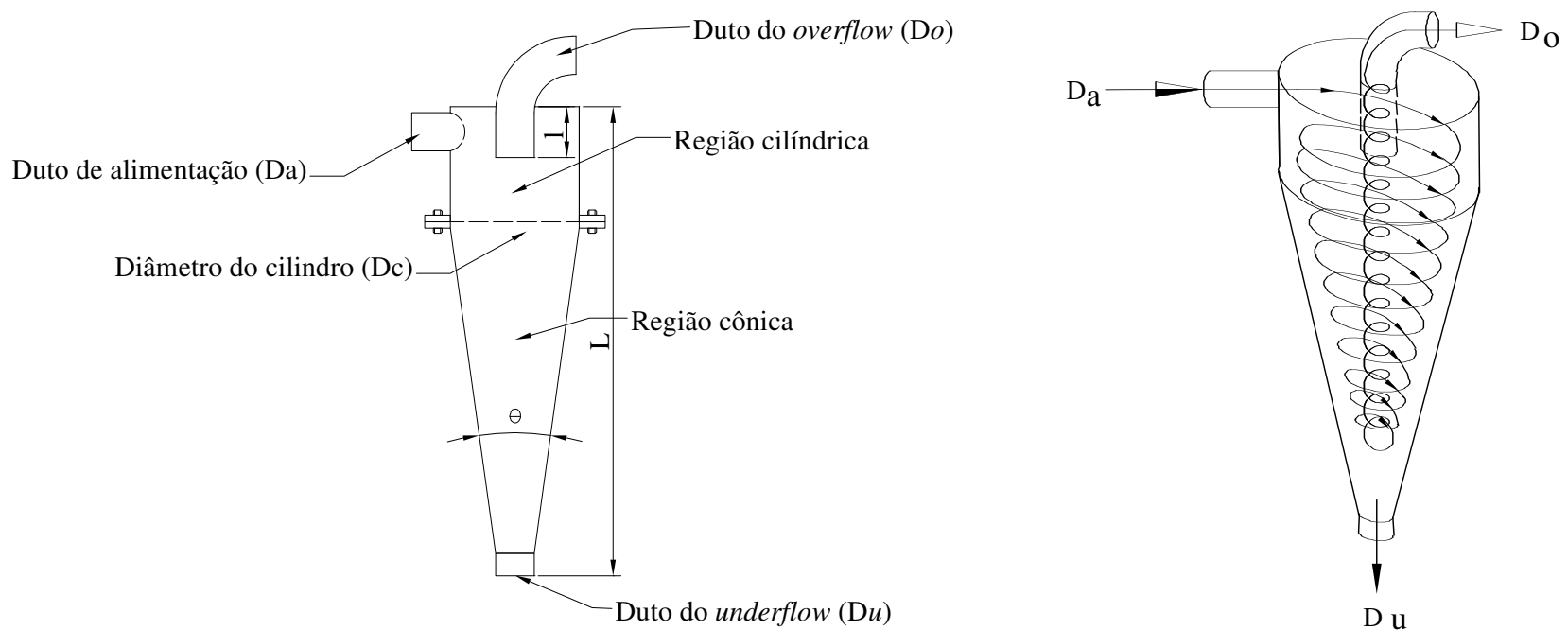

FIGURA 1. Esquema típico de um hidrociclone e princípio de seu funcionamento. Scheme of a typical hydrocyclone and principle of its operation.

BARROZO et al. (1992) relatam que o princípio de separação dos hidrociclones é o mesmo das centrífugas, proporcionado pela sedimentação centrífuga, nos quais as partículas em suspensão são submetidas a um campo centrífugo que provoca sua separação do fluido. A alimentação tangencial de uma suspensão sólido-líquido na região cilíndrica do equipamento provoca a formação de um vórtex descendente, o que faz com que as partículas de maior densidade relativa sejam projetadas contra a parede e arrastadas até a saída inferior do mesmo (underflow). Já as partículas menores são arrastadas para o centro do equipamento, formando um vórtex ascendente, saindo por um orifício superior (overflow) (Figura 1).

De forma distinta das centrífugas, os hidrociclones não apresentam partes móveis, requerendo baixo custo de instalação, pouca manutenção e simplicidade de operação (VIEIRA, 2006).

Segundo CABELLO (1996), as perdas de carga nos hidrociclones são da ordem de 30 a $70 \mathrm{kPa}$, dependem da vazão, porém são independentes do conteúdo de sedimentos e constantes no 
tempo, diferentes de sistemas de filtragem em que as perdas de carga aumentam à medida que se acumulam sedimentos.

Os hidrociclones são agrupados em famílias, possuindo como característica a proporção entre suas medidas geométricas associadas com o diâmetro da parte cilíndrica (Dc). As famílias de hidrociclones mais conhecidas e de maior interesse são as de geometria "RIETEMA", "BRADLEY" e "KREBS" (VIEIRA, 2006). As principais relações geométricas referentes a essas famílias de hidrociclones são apresentadas na Tabela 1.

TABELA 1. Proporções geométricas das "famílias" de hidrociclones. Geometric proportions of the hydrocyclones' families.

\begin{tabular}{cccccc}
\hline Hidrociclone & Da/Dc & Do/Dc & 1/Dc & L/Dc & $\theta$ \\
\hline RIETEMA & 0,280 & 0,340 & 0,400 & 5,000 & $15-20,0^{\circ}$ \\
BRADLEY & 0,133 & 0,200 & 0,330 & 6,850 & $9,0^{\circ}$ \\
KREBS & 0,267 & 0,159 & - & 5,874 & $12,7^{\circ}$ \\
\hline
\end{tabular}

Fonte: Adaptado de VIEIRA (2006)

Segundo SILVA \& MEDRONHO (1988), as principais variáveis associadas ao estudo do desempenho dos hidrociclones são: a eficiência total (ET) e a eficiência total reduzida (ET'). A eficiência total do hidrociclone é definida pela razão entre a massa total de sólidos coletados no concentrado (underflow) e a massa total de sólidos coletados na alimentação, sendo calculada pela eq.(1):

$$
\mathrm{ET}=\frac{\mathrm{W}_{\mathrm{su}}}{\mathrm{W}_{\mathrm{sa}}}=\frac{\mathrm{C}_{\mathrm{wu}} \mathrm{W}_{\mathrm{u}}}{\mathrm{C}_{\mathrm{wa}} \mathrm{W}_{\mathrm{a}}}
$$

em que,

ET - eficiência total, adimensional;

$\mathrm{W}_{\mathrm{su}}$ - vazão mássica de sólidos recuperados no underflow, $\mathrm{kg} \mathrm{s}^{-1}$;

$\mathrm{W}_{\mathrm{sa}}$ - vazão mássica de sólidos na alimentação, $\mathrm{kg} \mathrm{s}^{-1}$;

$\mathrm{C}_{\mathrm{wu}}$ - concentração mássica de sólidos no underflow, adimensional;

$\mathrm{C}_{\mathrm{wa}}$ - concentração mássica de sólidos na alimentação, adimensional;

$\mathrm{W}_{\mathrm{u}}$ - vazão mássica da suspensão no underflow, $\mathrm{kg} \mathrm{s}^{-1}$, e

$\mathrm{W}_{\mathrm{a}}$ - vazão mássica da suspensão na alimentação, $\mathrm{kg} \mathrm{s}^{-1}$.

No hidrociclone, parte da massa sólida não é separada devido à ação centrífuga, pois o equipamento também age como um divisor do escoamento, tal como uma conexão "T" em tubulações (SILVA, 1989). A esse fenômeno dá-se a denominação de "Efeito T", correlacionando-o diretamente com a razão de líquido (RL) que é calculada pela Equação 2.

$$
\mathrm{RL}=\frac{\mathrm{Qu}(1-\mathrm{Cvu})}{\mathrm{Qa}(1-\mathrm{Cva})}
$$

em que,

RL - razão de líquido, adimensional;

$\mathrm{Qu}$ - vazão volumétrica da suspensão no underflow, $\mathrm{L} \mathrm{s}^{-1}$;

Qa - vazão volumétrica da suspensão na alimentação, $\mathrm{L} \mathrm{s}^{-1}$;

Cvu - concentração volumétrica de sólidos no underflow, $\mathrm{L} \mathrm{L}^{-1}, \mathrm{e}$

Cva - concentração volumétrica de sólidos na alimentação, $\mathrm{L} \mathrm{L}^{-1}$.

A eficiência total reduzida demonstra o real desempenho do hidrociclone, pois considera o "fluxo morto", devido ao "Efeito T", o qual deve ser subtraído da eficiência total (ET). Para quantificação deste parâmetro, utiliza-se da eq.(3): 


$$
\mathrm{ET}^{\prime}=\frac{\mathrm{ET}-\mathrm{RL}}{1-\mathrm{RL}}
$$

em que,

ET'- eficiência total reduzida, adimensional;

ET - eficiência total, e

RL - razão de líquido.

VIEIRA (2006) comenta que, independentemente do modo como o hidrociclone esteja separando partículas, quer seja pelo arraste que o líquido proporciona (Efeito T), quer seja pela ação efetiva do campo centrífugo, a eficiência total (ET) considera todos os sólidos coletados no underflow, indistintamente daquilo que os levou a serem classificados. Já a eficiência total reduzida (ET') considera apenas aqueles sólidos coletados no underflow pelo efeito do campo centrífugo.

Avaliando o desempenho de um hidrociclone de geometria "Rietema" como pré-filtro de suspensão aquosa com areia, SOCCOL et al. (2005) obtiveram eficiências totais de 70 a $97 \%$. Em experimentos realizados por VIEIRA et al. (2001), foram observadas eficiências totais de 55 a $78 \%$. Eles testaram um hidrociclone "Rietema" como pré-filtro de suspensão aquosa com um minério denominado pirocloro, o qual apresenta diâmetro de partículas de 10 a 50 micrômetros.

Segundo KELLER \& BLIESNER (1990), os hidrociclones desempenham importante papel, pois se caracterizam pelo poder de separação de partículas presentes na água, mantendo constante a perda de carga ao longo do tempo, o que não ocorre com os outros tipos de filtros normalmente utilizados em sistemas de irrigação.

Os hidrociclones são usados de maneira diversificada nas indústrias química, metalúrgica, têxtil, petroquímica, de alimento, de bioengenharia, dentre outras (SILVA, 1989; ROVINSKY, 1995; DAI et al., 1999; CHU et al., 2002). SOCCOL (2003) comenta que, apesar de terem seu uso difundido em outras áreas do conhecimento, os hidrociclones não têm sido utilizados no Brasil com a mesma frequência que o são em sistemas de irrigação de países como Israel e Estados Unidos. Verificam-se várias pesquisas no campo da engenharia química, de minas e de alimento, que informam sobre o desempenho dos pré-filtros, denominados de hidrociclone. Entretanto, poucas pesquisas têm sido desenvolvidas acerca da avaliação deste equipamento como dispositivo de separação de partículas sólidas na água de irrigação.

Dessa forma, este trabalho teve como objetivo determinar a perda de carga proporcionada pelo hidrociclone de geometria "Rietema", bem como avaliar a capacidade em separar partículas sólidas presentes na água de irrigação em diferentes condições operacionais, utilizando-se, como parâmetros de desempenho, da eficiência total e da eficiência total reduzida.

\section{MATERIAL E MÉTODOS}

O experimento foi conduzido nas intermediações do laboratório de hidráulica no Centro Federal de Educação Tecnológica de Uberaba (CEFET-Uberaba), em Minas Gerais. Para a condução dos trabalhos, montou-se uma bancada de ensaio (Figura 2), onde foram instalados os seguintes equipamentos: reservatório com capacidade de 5.000 litros para a suspensão de água-areia e água-solo; conjunto motobomba, potência $11 \mathrm{~kW}$; chave de partida contactora com relê de sobrecarga; manômetro tipo Bourdon (previamente calibrado); registro de gaveta de diâmetro nominal 2"; tubos de PVC de diâmetro nominal 2"; manômetro diferencial com coluna de mercúrio em "U"; medidores de vazão tipo placa de orifício que foram construídos e previamente calibrados; hidrociclone de geometria "Rietema" com diâmetro do cilindro (Dc) de 19,20 cm, fabricado em aço galvanizado pela empresa GALLO Irrigação e Equipamentos Agrícolas (Figura 3); agitador submersível composto por um motorredutor elétrico, com potência de $1,1 \mathrm{~kW}$ e um dispositivo tipo hélice interligados, que permaneceu dentro do reservatório, circulando a suspensão, para mantê-la homogeneizada durante todo o tempo de avaliação. 


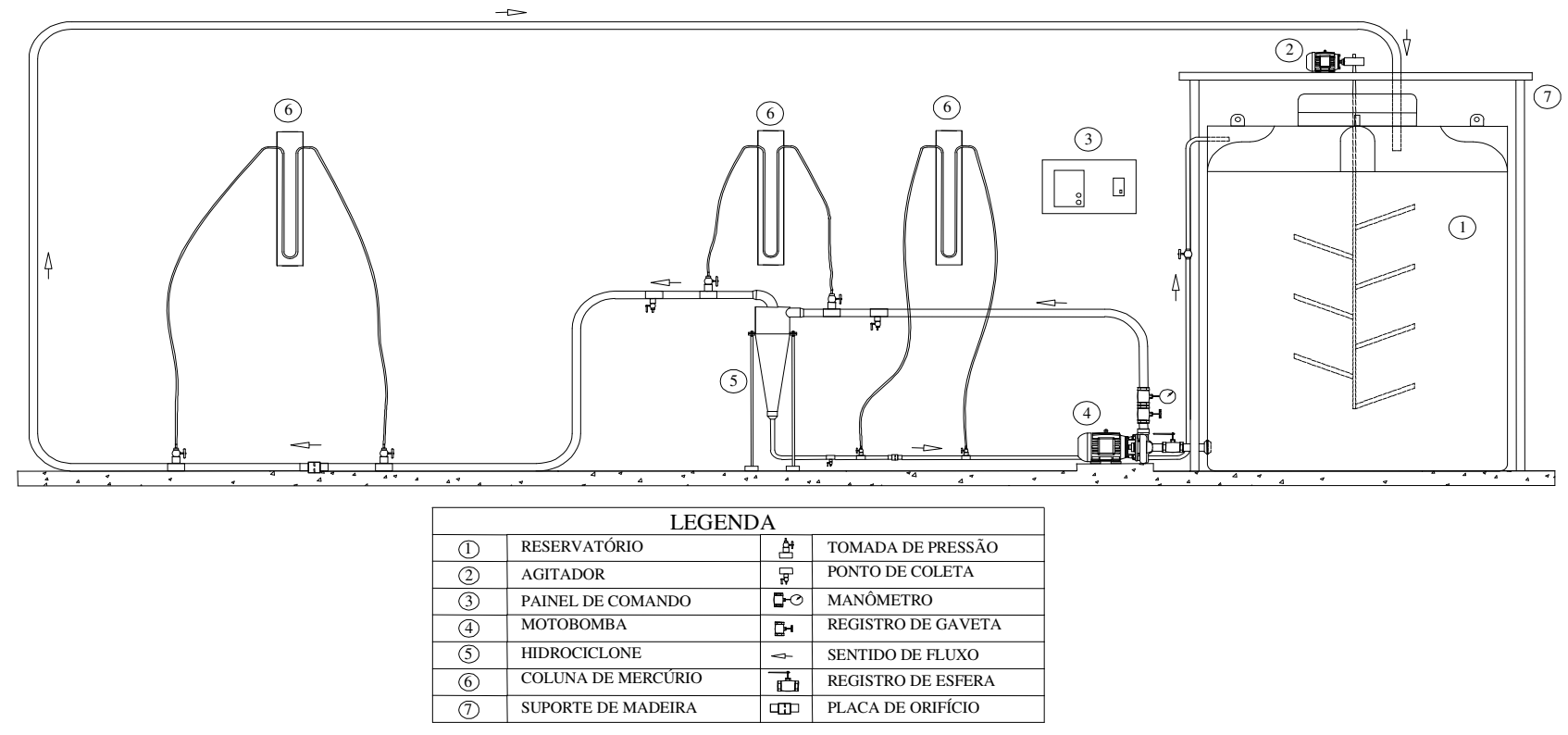

FIGURA 2. Esquema da bancada do experimento com hidrociclone de geometria "Rietema". Scheme of the bench of the experiment with the geometry hydrocyclone "Rietema".
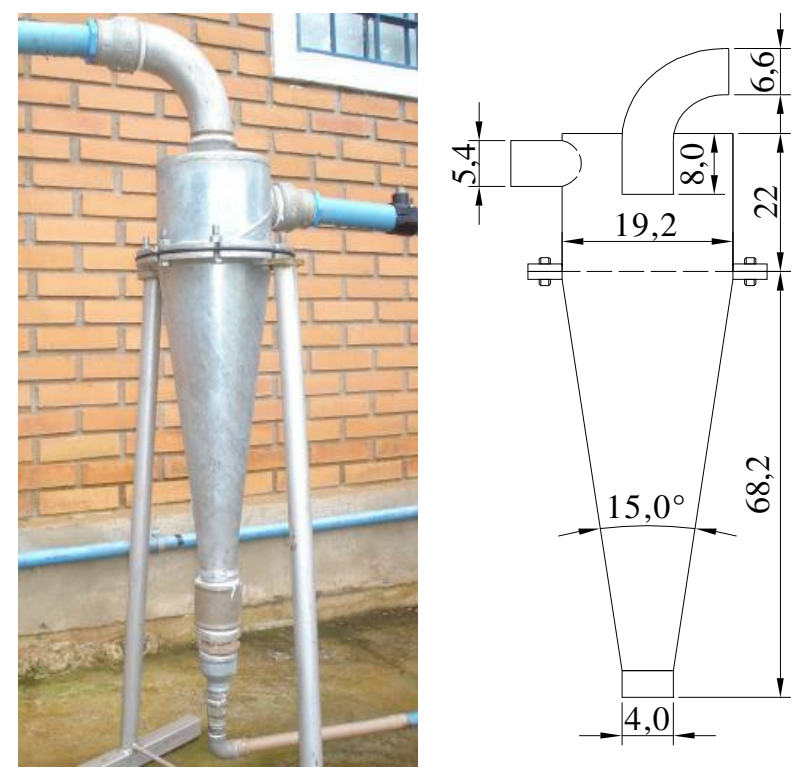

FIGURA 3. Hidrociclone de geometria "Rietema", com dimensões em centímetros. Geometry hydrocyclone "Rietema, with dimensions in centimeters.

A bancada de ensaios foi colocada em operação por meio do acionamento do conjunto motobomba, aproximadamente 30 minutos após acionado o agitador submersível. Por intermédio do comando de um registro de gaveta instalado no recalque da bomba, foi fixada a vazão desejada no hidrociclone, pelo conhecimento prévio das curvas ajustadas (pressão x vazão) nas placas de orifício instaladas nos dutos do overflow e underflow. A vazão volumétrica de alimentação consistiu na soma das vazões observadas nas placas de orifícios instaladas nos dutos do overflow e underflow.

Os ensaios foram conduzidos para vazões variando de 10 a $27 \mathrm{~m}^{3} \mathrm{~h}^{-1}$, com razão de líquido ajustada para aproximadamente $8 \%$, por meio do comando de um registro de gaveta instalado no duto do underflow. Durante o tempo de coleta dos dados de vazão e queda de pressão, tomavam-se amostras da suspensão nos três pontos de coleta (alimentação, overflow e underflow). Este 
procedimento foi repetido mais duas vezes, obtendo-se a média de três repetições para cada vazão. Em seguida, pesava-se a mesma, obtendo a massa da suspensão na referida corrente. A concentração mássica nas correntes foi obtida pelo método gravimétrico, utilizando-se de uma estufa para a retirada de toda água da suspensão. Dessa forma, conhecendo-se a massa de sólidos e a massa da suspensão nas amostras, foi possível determinar a concentração mássica de sólidos nas correntes de alimentação e underflow. A massa específica das suspensões, nas devidas correntes, foi determinada por meio de um balão volumétrico $(500 \mathrm{~mL})$, a partir do conhecimento da massa da suspensão e do volume do balão. A vazão mássica consistiu no produto da vazão volumétrica pela massa específica da suspensão caracterizada nas correntes de alimentação e underflow.

O experimento ocorreu em duas etapas: na primeira, utilizou-se de solo como material particulado e, na segunda, areia. Ao final de cada etapa, todo o sistema foi limpo, e o reservatório recomposto com água e material em avaliação (solo ou areia). A quantidade de material particulado (areia e solo) colocado no reservatório foi de $30 \mathrm{~kg}$, caracterizando uma concentração de $6.000 \mathrm{mg} \mathrm{L}^{-1}$. O solo, de classe textural franco-argilo-arenosa (60\% de areia, $14 \%$ de silte e $26 \%$ de argila), foi coletado no Câmpus I do CEFET Uberaba, e a areia (98\% de areia e 2\% de argila) proveniente do assoreamento, no Rio Lanoso, afluente do Rio Uberaba. As análises texturais e as massas específicas do solo $\left(2.650 \mathrm{~kg} \mathrm{~m}^{-3}\right)$ e da areia $\left(2.700 \mathrm{~kg} \mathrm{~m}^{-3}\right)$ foram determinadas no laboratório de solos da EPAMIG (Empresa de Pesquisa Agropecuária de Minas Gerais). A perda de carga do equipamento foi determinada utilizando um manômetro diferencial de coluna em " $U$ " com mercúrio, para cada vazão amostrada, sendo que as tomadas de pressão foram instaladas a uma distância mínima de dez vezes o diâmetro da tubulação antes e depois do hidrociclone, procedimento recomendado para evitar transientes hidráulicos que possam interferir nas determinações de pressão (AZEVEDO NETTO et al. 1998).

Os dados observados foram usados para calcular a perda de carga em função das vazões testadas, aplicando o princípio de conservação de energia (Teorema de Bernoulli), utilizando-se de uma planilha eletrônica do Office "EXCEL" da Microsoft. Com o auxílio do software "MATHCAD" e utilizando-se das eqs.(1), (2) e (3) propostas por SVAROVSKY (2000), quantificou-se o desempenho do hidrociclone para as vazões testadas.

\section{RESULTADOS E DISCUSSÃO}

Na Tabela 2, estão apresentados os valores obtidos com o desempenho do hidrociclone para as vazões ensaiadas. Verificou-se que a eficiência total de remoção do hidrociclone apresentou valores que variaram de $30,06 \%$ a $92,31 \%$, respectivamente, para vazões de $12,43 \mathrm{~m}^{3} \mathrm{~h}^{-1}$ a $26,97 \mathrm{~m}^{3} \mathrm{~h}^{-1}$, utilizando-se de suspensão aquosa com areia.

Quando foi utilizada suspensão aquosa com solo, verificou-se um decréscimo na eficiência total que variou de $19,59 \%$ a 54,29\%, respectivamente, para as vazões $10,07 \mathrm{~m}^{3} \mathrm{~h}^{-1}$ a $26,21 \mathrm{~m}^{3} \mathrm{~h}^{-1}$. Esta diminuição da eficiência total ocorreu devido às diferenças texturais do material particulado usado. Já o decréscimo da eficiência com a diminuição da vazão é explicado pelo menor efeito centrífugo, em função da menor velocidade terminal das partículas sólidas no interior do equipamento. VIEIRA et al. (2001), em trabalho conduzido com suspensão de pirocloro, avaliando um hidrociclone de geometria "Rietema", também verificaram decréscimo na eficiência total de remoção, com a diminuição dos diferenciais de pressão. PEÇANHA \& MASSARANI (1980) comentam que hidrociclones bem projetados operam com eficiência total de remoção na faixa de 80 a 90\%. Em avaliação de um hidrociclone "Rietema" para remoção de areia, SOCCOL et al. (2005) observaram decréscimo da eficiência total com o aumento do diferencial de pressão, isto é, com o aumento da vazão de alimentação. MAILAPALLI et al. (2007) testaram um hidrociclone de geometria "Rietema" e concluíram que o equipamento é ineficiente em remover partículas sólidas pequenas, como argila. Pela Tabela 2, verifica-se ainda que a razão de líquido manteve-se próxima do valor proposto na metodologia para as suspensões com areia e solo, em torno de $8 \%$. 
TABELA 2. Valores médios obtidos para o hidrociclone operando com suspensões de areia e solo. Average values obtained for the hydrocyclone operating with sand and soil suspensions.

\begin{tabular}{ccccccc}
\hline $\begin{array}{c}\text { Qa } \\
\left(\mathrm{m}^{3} \mathrm{~h}^{-1}\right)\end{array}$ & $\begin{array}{c}\mathrm{Qu} \\
\left(\mathrm{m}^{3} \mathrm{~h}^{-1}\right)\end{array}$ & $\begin{array}{c}\mathrm{RL} \\
(\%)\end{array}$ & $\begin{array}{c}\text { Wsa } \\
\left(\mathrm{kg} \mathrm{h}^{-1}\right)\end{array}$ & $\begin{array}{c}\text { Wsu } \\
\left(\mathrm{kg} \mathrm{h}^{-1}\right)\end{array}$ & $\begin{array}{c}\text { ET } \\
(\%)\end{array}$ & $\begin{array}{c}\text { ET' } \\
(\%)\end{array}$ \\
\hline \multicolumn{7}{c}{ Suspensão com areia } \\
\hline 26,97 & 2,28 & 8,45 & 10,31 & 9,52 & 92,31 & 91,60 \\
22,78 & 1,90 & 8,34 & 5,43 & 4,05 & 74,60 & 72,29 \\
20,54 & 1,70 & 8,29 & 4,51 & 2,56 & 56,75 & 52,84 \\
18,21 & 1,46 & 8,01 & 3,72 & 1,68 & 45,14 & 40,36 \\
15,88 & 1,28 & 8,04 & 3,35 & 1,23 & 36,78 & 31,25 \\
12,43 & 0,98 & 7,89 & 2,43 & 0,73 & 30,06 & 24,07 \\
\hline \multicolumn{7}{c}{ Suspensão com solo } \\
\hline 26,21 & 2,27 & 8,66 & 24,64 & 13,38 & 54,29 & 49,96 \\
23,08 & 2,00 & 8,66 & 15,40 & 6,95 & 45,12 & 39,91 \\
19,56 & 1,67 & 8,52 & 12,75 & 4,23 & 33,18 & 26,96 \\
16,67 & 1,40 & 8,40 & 10,26 & 2,44 & 23,78 & 16,80 \\
13,01 & 1,12 & 8,63 & 7,12 & 1,60 & 22,48 & 15,16 \\
10,07 & 0,88 & 8,74 & 4,34 & 0,85 & 19,59 & 11,86 \\
\hline
\end{tabular}

Qa - vazão volumétrica na alimentação; Qu - vazão volumétrica no underflow; RL - razão de líquido; Wsa - vazão mássica de sólidos na alimentação; Wsu - vazão mássica de sólidos no underflow; ET - eficiência total; ET' - eficiência total reduzida.

É oportuno ressaltar que o equipamento recuperou na corrente do underflow $9,52 \mathrm{~kg} \mathrm{~h}^{-1} \mathrm{e}$ $13,38 \mathrm{~kg} \mathrm{~h}^{-1}$ dos $10,31 \mathrm{~kg} \mathrm{~h}^{-1}$ e $24,64 \mathrm{~kg} \mathrm{~h}^{-1}$ de massa sólida alimentada no hidrociclone para as suspensões com areia e solo, respectivamente (Tabela 2). Isso significa, hipoteticamente, o que seria lançado em um sistema de irrigação sem o uso do hidrociclone, demandando maior controle e manejo dos sistemas de filtragens. Na Figura 4, são apresentadas curvas de perdas de carga ocorridas no hidrociclone, podendo-se observar que a perda de carga aumentou em função da vazão. Assim, com o aumento do efeito centrífugo, cria-se maior turbulência do fluxo no interior do equipamento que eleva a perda de carga.

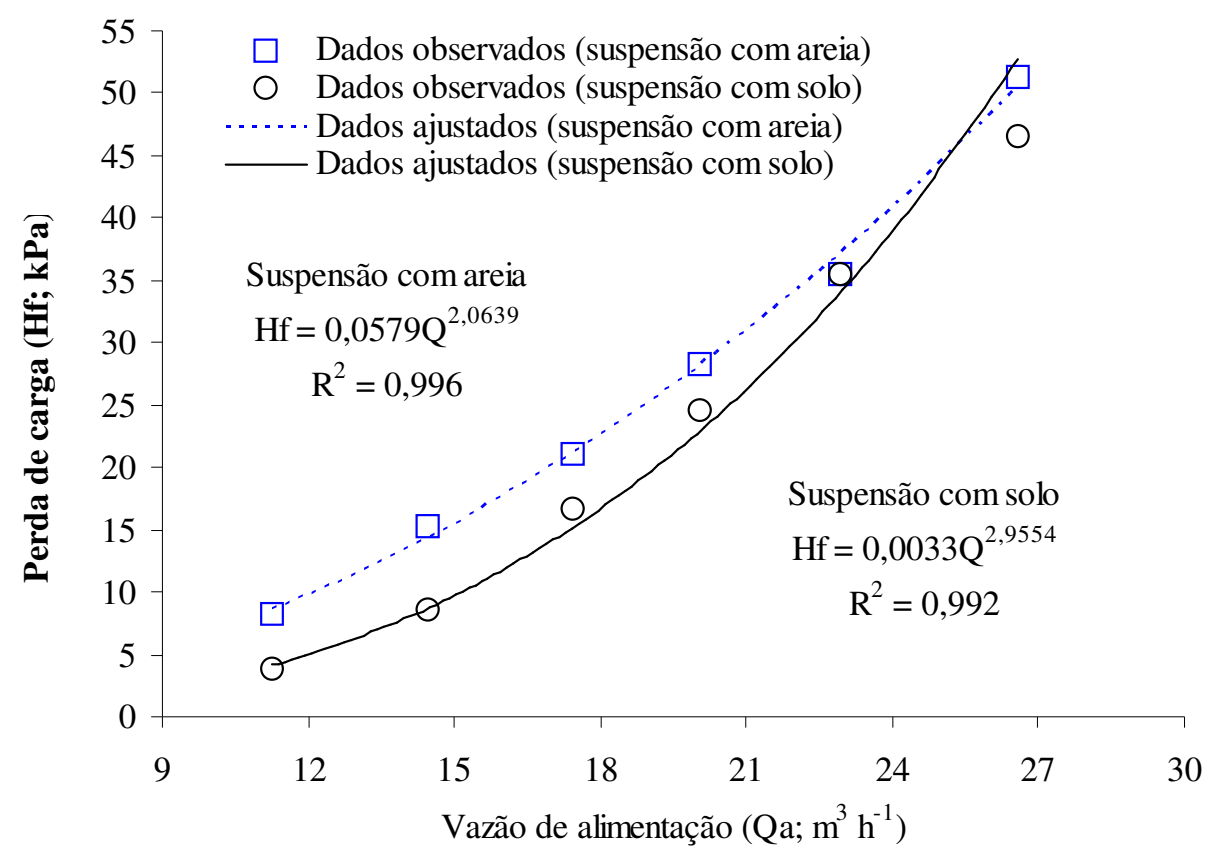

FIGURA 4. Variação da perda de carga em função da vazão de alimentação no hidrociclone com suspensões de areia e solo. Variation of pressure loss as a function of feed flow in the hydrocyclone with sand and soil suspensions. 
Verificou-se que as perdas de carga variaram de $4 \mathrm{kPa}$ a $52 \mathrm{kPa}$ para as variações de vazão de $10 \mathrm{~m}^{3} \mathrm{~h}^{-1}$ a $27 \mathrm{~m}^{3} \mathrm{~h}^{-1}$ em suspensões de areia e solo, em conformidade com o apresentado por CABELLO (1996). A perda de carga máxima no hidrociclone de geometria "Rietema" foi em média $50 \mathrm{kPa}$ para vazão média máxima de $26,6 \mathrm{~m}^{3} \mathrm{~h}^{-1}$. As equações de perda de carga obtidas em função da variação do fluxo da suspensão com areia e solo apresentaram elevados coeficientes de ajuste para o modelo potencial, em conformidade com SOCCOL (2003) e MAILAPALLI et al. (2007). Observa-se que a perda de carga no hidrociclone depende do material particulado em separação, indicando que a areia (de maior granulometria) apresenta maiores valores de perda de carga. Isso pode ser explicado pelo fato de o solo, por apresentar menor granulometria, permitir maior índice de colmatação no interior do equipamento, e a suspensão com areia, consequentemente, apresenta maior atrito no interior do hidrociclone.

\section{CONCLUSÕES}

A perda de carga no hidrociclone avaliado aumentou potencialmente com o acréscimo da vazão de alimentação. alimentação.

A eficiência total do hidrociclone testado aumentou com o acréscimo da vazão de

O hidrociclone avaliado foi eficiente na remoção de partículas sólidas, notadamente para água contendo areia, sendo recomendado como pré-filtro em sistemas de irrigação.

\section{REFERÊNCIAS}

AZEVEDO NETTO, J.M.; FERNANDES, M.F.; ARAUJO, R.; ITO, A.E. Manual de hidráulica. 8. ed. São Paulo: Edgard Blücher, 1998. 669p.

AYERS, R.S.; WESTCOT, D.W. A qualidade da água na agricultura. Tradução H.R. Gheyi; J.F. de Medeiros; F.A.V. Damasceno. Campina Grande: UFPB, 1991. 218p.

BARROZO, M.A.S.; DAMASCENO, J.J.R.; LANNA, A.E. Estudo do desempenho de um hidrociclone filtrante. Revista Ciência \& Engenharia, Uberlândia, v.1, p.175-86, 1992.

BERNARDO, S.; SOARES, A.A.; MANTOVANI, E.C. Manual de irrigação. 7. ed. Viçosa: UFV, 2005. 611p.

CABELLO, F.P. Riegos localizados de alta frecuencia: goteo, microaspersion, exudacion. $3^{\text {rd }}$ ed. Madri: Mundi-Prensa, 1996. 513 p.

CHU, L.Y.; CHEN, W.M.; LEE, X.Z. Enhancement of hydrocyclone performance by controlling the inside turbulence structure. Chemical Engineering Science, London, v.57, n.1, p.207-212, 2002.

DAI, G.Q.; LI, J.M.; CHEN, W.M. Numerical prediction of the liquid flow within a hydrocyclone. Chemical Engineering Journal, Lawrence, v.74, n.3, p.217-223, 1999.

KELLER, J.; BLIESNER, R.D. Sprinkler and trickle irrigation. New York: Van Nostrand Reinhold, 1990. 652 p.

NAKAYAMA, F.S.; BUCKS, D.A. Water quality in drip/trickle irrigation - a review. Irrigation Science, New York, v.12, n.4, p.187-192, 1991.

MAILAPALLI, D.R.; MARQUES, P.A.A.; THOMAS, K.J. Performance evaluation of hydrocyclone filter for microirrigation. Engenharia Agrícola, Jaboticabal, v.27, n.2, p.373-382, 2007.

PEÇANHA, R.P.; MASSARANI, G. Avaliação do desempenho de hidrociclones. Revista Brasileira de Tecnologia, Rio de Janeiro, v.11, n.4, p.289-299, 1980. 
ROVINSKY, L.A. Application of separation theory to hydrocyclone design. Journal of Food Engineering, London, v.26, n.2, p.131-146, 1995.

SILVA, M.A.P. da. Hidrociclones de Bradley: dimensionamento e análise de desempenho. 1989. 81 f. Dissertação (Mestrado em Engenharia Química) - Universidade Federal do Rio de Janeiro, Rio de Janeiro, 1989.

SILVA, M.A.P.; MEDRONHO, R.A. Modelos que preveem o desempenho de hidrociclones: uma avaliação crítica. In: ENCONTRO SOBRE ESCOAMENTO EM MEIOS POROSOS, 16., 1988, Petrópolis. Anais... p.351-361.

SOCCOL, O.J. Construção e avaliação de hidrociclone para pré-filtragem da água de irrigação. 2003. 89 f. Tese (Doutorado em Agronomia) - Escola Superior de Agricultura "Luiz de Queiroz", Universidade São Paulo, Piracicaba, 2003.

SOCCOL, O.J.; BOTREL, T.A.; GERVÁSIO, E.S.; ULLMANN, M.N. Avaliação de um hidrociclone de "Rietema" para remoção de areia da água de irrigação. Revista Brasileira de Engenharia Agrícola e Ambiental, Campina Grande, v.9, n.4, p.464-468, 2005.

SOUZA, F.J.; VIEIRA, L.G.M.; DAMASCENO, J.J.R.; BARROZO, M.A.S. Analysis of the influence of the filtering medium on the behavior of the filtering hydrocyclones. Power Technology, Lausanne, v.107, n.3, p.259-267, 2000.

SVAROVSKY, L. Solid-liquid separation. $2^{\text {nd }}$. ed. London: Butterworths, 2000. 568 p.

THAME, A.C.M. Água: a iminência da escassez. São Paulo: SRHSO/SP, 2000. p.1-12.

THOMPSON, G.T.; SPIESS, L.B.; KRIDER, J.N. Farm resources and system selection. In: JENSEN, M. E. (Ed.). Design and operation of farm irrigation systems. St. Joseph: ASAE, 1983. cap. 3, p.45-76.

VIEIRA, L.G.M. Otimização dos processos de separação em hidrociclones filtrantes. 2006. $298 \mathrm{f}$. Tese (Doutorado em Engenharia Química) - Faculdade de Engenharia Química, Universidade Federal de Uberlândia, Uberlândia, 2006.

VIEIRA, L.G.M.; BARBOSA, E.A.; FUTIWAKI, L.; DAMASCENO, J.J.R.; BARROZO, M.A.S. Estudo de um hidrociclone filtrante segundo a geometria de "Rietema". In: CONGRESSO BRASILEIRO DE SISTEMAS PARTICULADOS, 28., 2000, Teresópolis. Anais... Rio de Janeiro: UFRJ, 2001. p.279-285. 